\title{
Degradabilidade ruminal da matéria seca e da proteína bruta de folhas e folíolos de forrageiras tropicais ${ }^{1}$
}

\section{Cristina Mattos Veloso 2,5, Norberto Mario Rodriguez ${ }^{3,5}$, Gleidson Giordano Pinto de Carvalho4, Aureliano José Vieira Pires ${ }^{2,5}$, Gerson Barreto Mourão ${ }^{3}$, Lúcio Carlos Gonçalves ${ }^{3,5}$, Ivan Barbosa Machado Sampaio 3,5}

\footnotetext{
1 Parte da dissertação de Mestrado do primeiro autor apresentada à UFMG, MG.

2 Universidade Estadual do Sudoeste da Bahia - UESB, DTRA, Itapetinga, BA.

${ }^{3}$ Universidade Federal de Minas Gerais - UFMG, DZO, Belo Horizonte, MG.

${ }^{4}$ Pós-Graduação em Zootecnia, UFV, Viçosa, MG, Bolsista do CNPq.

5 Pesquisadores do CNPq.
}

RESUMO - Foram determinadas as degradabilidades in situ da MS e PB dos folíolos de três leguminosas tropicais - leucena (Leucaena leucocephala (Lam.) de Wit), guandu (Cajanus cajan (L.) Millsp.) e soja perene (Neonotonia wightii) - e de folhas de outras duas forrageiras tropicais - rami (Boehmeria nivea (L.) Gaudich) e mandioca (Manihot esculenta Crantz). Amostras de $3 \mathrm{~g}$ (guandu, soja e rami) ou $5 \mathrm{~g}$ (leucena e mandioca) do material foram incubadas no rúmen de quatro novilhos por períodos de 3,6,12,18, 24 e 48 horas. As degradabilidades efetivas da MS e da PB para a taxa de passagem de $5 \%$ hora foram elevadas (acima de 60\%). As taxas de degradação, exceto a do guandu, também foram consideradas elevadas. As forrageiras apresentaram alta digestibilidade total da proteína (acima de $88 \%$ ), exceto os folíolos de guandu (69\%). O guandu foi a forrageira com menor potencial de degradação da proteína.

Palavras-chave: bovinos, incubação ruminal, leguminosa

\section{Ruminal degradabilities of dry matter and crude protein of tropical forages}

\begin{abstract}
In situ DM and CP degradabilities of leaflets of three tropical legumes: leucaena (Leucaena leucocephala (Lam.) de Wit), pigeon pea (Cajanus cajan (L.) Millsp.), and glycine (Neonotonia wightii) and of leaves of two other tropical forages: ramie (Boehmeria nivea (L.) Gaudich) and cassava (Manihot esculenta Crantz) were determined in this trial. Three grams of pigeon pea, glycine, and ramie and $5 \mathrm{~g}$ of leucaena and cassava were incubated in the rumen of four steers for $3,6,12,18$, 24 , and 48 hours. Effective degradabilities of DM and CP assuming a passage rate of 5\%/hour were greater than $60 \%$. Degradation rates, except for pigeon pea, were also high in this study. Forages had high total digestibility of protein (greater than $88 \%$ ), except for pigeon pea leaflets that was $69 \%$. Pigeon pea was the forage with the lowest potential for ruminal protein degradation.
\end{abstract}

Key Words: cattle, ruminal incubation, legumes

\section{Introdução}

As regiões de clima tropical possuem alto potencial de produção de forragens. No entanto, a produtividade animal nestas regiões é baixa se comparada à de regiões temperadas, pois as plantas tropicais produzem grande quantidade de matéria seca de baixo valor nutritivo. Segundo Broderick (1995), normalmente as leguminosas apresentam taxas de degradação e a degradabilidade dos nutrientes mais altas que às gramíneas. Como a fonte de proteína para a alimentação animal é um dos fatores mais limitantes da produção, torna-se indispensável o estudo da utilização de forrageiras tropicais ricas em proteína e de menor custo.
O conhecimento da degradabilidade ruminal das diferentes frações dos alimentos e, especialmente, da proteína é de grande importância (Tonani et al., 2001), pois permite alterar os ingredientes utilizados nas rações, possibilitando maximizar a produtividade e minimizar os custos. Além disso, permite identificar fatores que afetam o consumo voluntário de forragens, como o grau de maturidade, a relação caule-folha e a forma de processamento (Ladeira et al., 2001).

A técnica dos sacos de náilon tem sido amplamente utilizada com esse propósito, constituindo-se em uma alternativa viável, principalmente por sua simplicidade e economicidade (Ruggieri et al., 2001; Molina et al., 2002a, Molina et al., 2002b). 
A degradação ruminal dos alimentos é fundamental para se avaliar a qualidade do nutriente (Moreira et al., 2003) e a quantidade de nutrientes disponível para os microrganismos no rúmen que chega ao intestino (Barbosa et al., 1998). Como os microrganismos do rúmen degradam as fontes protéicas, produzindo nitrogênio amoniacal (Queiroz et al., 1998), a técnica in situ tem sido adotada como metodologia padrão para caracterização da degradabilidade ruminal do nitrogênio, por fornecer melhores comparações com os resultados in vivo (Molina et al., 2002a).

A determinação da degradabilidade no rúmen, sem considerar a taxa de passagem, pode superestimar a extensão da degradação, uma vez que as partículas dos alimentos estão sujeitas à passagem para o compartimento seguinte antes de ser completamente degradadas (Ladeira et al., 2001).

A extensão da degradação de fontes protéicas no rúmen é variável e as diferenças estão relacionadas principalmente a fatores intrínsecos ao alimento, à espécie animal e às influências da natureza da dieta sobre o ambiente ruminal (Volden et al., 2002).

Neste trabalho objetivou-se determinar as degradações in situ da MS e da PB dos folíolos de três leguminosas tropicais: leucena (Leucaena leucocephala (Lam.) de Wit), guandu (Cajanus cajan (L.) Millsp.) e soja perene (Neonotonia wightii) e das folhas de outras duas forrageiras tropicais: rami (Boehmeria nivea (L.) Gaudich) e mandioca (Manihotesculenta Crantz).

\section{Material e Métodos}

Foram utilizados quatro novilhos mestiços EuropeuZebu, canulados no rúmen, com idade média de 24 meses e peso médio de $320 \mathrm{~kg}$. Os animais foram alimentados com uma dieta básica, composta de $60 \%$ de feno de capimbraquiária (Brachiaria decumbens Stapf) e $40 \%$ de concentrado comercial, com base na MS.

Amostras de $3 \mathrm{~g}$ (guandu, soja e rami) ou $5 \mathrm{~g}$ (leucena e mandioca) dos folíolos ou das folhas, conforme o caso (moídas a $2 \mathrm{~mm}$ ) foram incubadas no rúmen, em sacos de náilon (dimensões de $8 \times 15 \mathrm{~cm}$, com poros de $50 \mu \mathrm{m}$ ) durante $3,6,12,18,24$ e 48 horas. Para cada forrageira, mativeram-se três sacos como controle para se obter a estimativa do tempo de colonização (tempo zero $-\mathrm{t}_{0}$ ), lavando-os em água por 20 minutos, sem apertá-los.

Retirados do rúmen, os sacos foram imediatamente imersos em água fria e posteriormente lavados manualmente com água. Em seguida, foram secos em estufa de ventilação forçada a $65^{\circ} \mathrm{C}$, durante 48 horas, e pesados para determinação do desaparecimento de MS no rúmen.
A composição química das forrageiras estudadas foi obtida segundo metodologia descrita por Silva \& Queiroz (2002) e os resultados são descritos na Tabela 1.

O delineamento experimental utilizado foi o de parcelas subdivididas, composto por quatro bloco (animais), cinco tratamentos (forragens) e seis subtratamentos (horários de incubação dos alimentos no rúmen).

As degradações da MS e da PB das forrageiras, nos diversos tempos de incubação, foram calculadas pela equação:

$$
\mathrm{Dg}=\mathrm{A}-\mathrm{B} \cdot \mathrm{e}^{-\mathrm{ct}} \text { (Sampaio, 1988) }
$$

em que: $D g$ é a porcentagem de degradação após o tempo $\mathrm{t} ; A$, a porcentagem máxima de degradação do material contido no saco de náilon (fração imediatamente solúvel mais a fração insolúvel potencialmente degradável sob ação da microbiota); $B$, um parâmetro sem valor biológico de interesse (se não houvesse tempo de colonização, ele corresponderia ao total a ser degradado pela ação de microrganismos); $c$, a taxa constante de degradação da fração que permanece no saco de náilon; e $t$, o tempo de incubação no rúmen.

O tempo de colonização (TC) do material contido no saco foi calculado conforme a equação proposta por McDonald(1981):

$$
\mathrm{TC}=-1 / \mathrm{c} \times \operatorname{In}(\mathrm{A}-\mathrm{S}) / \mathrm{B}
$$

em que: $A, B$ e $c$ são os mesmos parâmetros definidos na equação anterior; e $S$, a fração solúvel, determinada pela porcentagem de desaparecimento no tempo zero de incubação.

Para calcular a degradabilidade efetiva (DE), foi utilizada a equação proposta por Ørskov \& McDonald (1979), considerando-se uma taxa de passagem $(k)$ de $5 \%$ /hora, sugerida para nível médio de consumo:

$$
\mathrm{DE}=\mathrm{S}+\left(\mathrm{B}_{1} \times \mathrm{c}\right) /(\mathrm{c}+\mathrm{k})
$$

Tabela 1 - Teores de MS, PB, FDN, FDA, NIDA e CNE dos folíolos e das folhas das forrageiras utilizadas para incubação ruminal

\begin{tabular}{|c|c|c|c|c|c|}
\hline $\begin{array}{l}\text { Componente } \\
\text { Component }\end{array}$ & $\begin{array}{l}\text { Leucena } \\
\text { Leucaena }\end{array}$ & $\begin{array}{c}\text { Guandu } \\
\text { Pigeon pea }\end{array}$ & $\begin{array}{l}\text { Soja } \\
\text { Soy }\end{array}$ & $\begin{array}{l}\text { Ramie } \\
\text { Glycine }\end{array}$ & $\begin{array}{c}\text { Mandioca } \\
\text { Cassava }\end{array}$ \\
\hline MS & 87,95 & 90,31 & 86,59 & 88,90 & 89,13 \\
\hline $\begin{array}{l}D M \\
\mathrm{~PB}^{*}\end{array}$ & 25,45 & 19,98 & 26,01 & 27,58 & 37,63 \\
\hline $\begin{array}{l}C P \\
\text { FDN }^{*}\end{array}$ & 37,06 & 58,22 & 50,06 & 26,18 & 43,74 \\
\hline $\begin{array}{l}N D F \\
\text { FDA }^{*}\end{array}$ & 13,43 & 41,96 & 28,84 & 14,52 & 30,04 \\
\hline $\begin{array}{l}A D F \\
\mathrm{NIDA}^{* *}\end{array}$ & 7,59 & 26,25 & 6,38 & 2,83 & 9,58 \\
\hline $\begin{array}{l}A D I N \\
\mathrm{CNE}^{*} \\
N S C\end{array}$ & 24,19 & 15,76 & 11,87 & 19,30 & 9,51 \\
\hline
\end{tabular}

Table 1 - Contents of DM, CP, NDF, ADF, ADIN, and NSC of leaflets and leaves of forage used in the incubation

$\%$ da MS, ${ }^{* *} \%$ do $\mathrm{N}$ total.

"\% of $D M,{ }^{* *} \%$ of total $N$ 
em que: $S$ e $c$ são como previamente definidos; e $B_{l}$ é a fração degradável, calculada subtraindo-se do potencial de degradação $A$, a fração solúvel $(S)\left(\mathrm{B}_{1}=\mathrm{A}-\mathrm{S}\right)$.

A proteína não degradada no rúmen (PNDR) e a proteína não degradada no rúmen digestível (PNDRD) foram calculadas conforme o AFRC (1993):

$$
\text { PNDR }=1-(\mathrm{a}+\mathrm{bc}) /(\mathrm{c}+\mathrm{k})
$$

em que: $a, b, c$ e $k$ correspondem a $S, B_{1}, c$ e $k$ da equação para o cálculo da $\mathrm{DE}$, respectivamente.

PNDRD $=0,9$ (PNDR $-6,25$ NIDA)

em que NIDA é nitrogênio insolúvel em detergente ácido.

\section{Resultados e Discussão}

Os parâmetros de degradação ruminal da MS e da $\mathrm{PB}$ das forrageiras estão apresentados, respectivamente, nas Tabelas 2 e 3 .

A degradabilidade potencial (DP, parâmetro $A$ ) da MS (Tabela 2) dos folíolos de leucena $(91,65 \%$ ) foi bastante elevada, de modo que quase a metade $(42,43 \%)$ foi degradada às 3 horas de incubação ruminal, o que se explica pelo baixo tempo de colonização (TC) desta fração (1,37 horas).

Os TC da MS e da PB dos folíolos de guandu foram relativamente longos e as taxas de fermentação foram baixas, resultando em início mais tardio da degradação destas frações (a partir de 12 horas).

O desaparecimento médio máximo (em torno de 82,78\%) da MS dos folíolos de soja ocorreu com 18 horas de fermentação no rúmen. Como os potenciais de degradação das frações em estudo foram atingidos após 48 horas de incubação ruminal, este período foi suficiente e adequado para

Tabela 2 - Parâmetros de degradação ruminal da MS de folíolos e folhas das forrageiras estudadas

Table 2 - Kinetics of ruminal DM degradation of leaflets and leaves of the studied forages

\begin{tabular}{lrcrrr}
\hline $\begin{array}{l}\text { Parâmetro } \\
\text { Item }\end{array}$ & $\begin{array}{r}\text { Leucena } \\
\text { Leucaena }\end{array}$ & $\begin{array}{c}\text { Guandu } \\
\text { Pigeon pea }\end{array}$ & $\begin{array}{c}\text { Soja } \\
\text { Soy }\end{array}$ & $\begin{array}{r}\text { Ramie } \\
\text { Glycine }\end{array}$ & $\begin{array}{c}\text { Mandioca } \\
\text { Cassava }\end{array}$ \\
\hline A (\%) & 91,65 & 63,60 & 81,26 & 91,82 & 87,36 \\
B (\%) & 62,93 & 43,44 & 60,33 & 73,29 & 73,09 \\
c (\%/h) & 6,00 & 3,90 & 17,60 & 10,20 & 10,60 \\
TC (h) & 1,37 & 5,72 & 1,74 & 3,31 & 1,76 \\
S (\%) & 33,67 & 28,84 & 36,82 & 39,53 & 26,71 \\
$\mathrm{~B}_{1}(\%)$ & 57,98 & 34,76 & 44,44 & 52,29 & 60,65 \\
DE (\%) k=0,05 & 65,30 & 44,07 & 71,43 & 74,62 & 67,92 \\
$\mathrm{R}^{2}(\%)$ & 94,05 & 85,38 & 94,85 & 94,69 & 96,84
\end{tabular}

$A=$ potencial de degradação, $B=$ fração degradável, obtida pela equação $\mathrm{P}=\mathrm{A}-\mathrm{Be}^{-\mathrm{ct}}, \mathrm{c}=$ taxa de degradação, $\mathrm{TC}=$ tempo de colonização, $\mathrm{S}=$ fração solúvel, que corresponde à porcentagem de desaparecimento no tempo zero, $B_{1}=$ fração degradável, obtida por $A-S, D E=$ degradabilidade efetiva, $\mathrm{k}=$ taxa de passagem, $\mathrm{R}^{2}=$ coeficiente de determinação.

$A=$ degradation potencial, $B=$ degradable fraction obtained from the equation $P=A-B e^{-c t}$, $c=$ degradation rate, $C T=$ colonization time $S=$ soluble fraction, which corresponds to zero time disappearance percentage, B1 = degradable fraction obtained from A-S, $E D=$ effective degradability,$k=$ passage rate, $R^{2}=$ coefficient of determination. a representação correta da degradação da MS e da PB dos folíolos de soja perene. Esses dados estão de acordo com os de Pulido \& Leaver (2000), que avaliaram a degradabilidade de forragens em diferentes alturas, com período máximo de 48 horas de incubação.

Para as folhas de rami, o desaparecimento médio 48 horas após a inserção no rúmen praticamente alcançou os valores da degradabilidade potencial, indicando que, para esta forrageira, assim como para a soja, não seria necessária a utilização de um período mais extenso de incubação ruminal.

As folhas de mandioca apresentaram altos potenciais e elevadas taxas de degradação para MS e PB, além de curtos TC. Estas características foram responsáveis pelo início da degradação destas frações às três horas de incubação ruminal e pelos valores relativamente altos de degradabilidade efetiva(DE). A degradação dos constituintes das folhas de mandioca foi alta, visto que, com seis horas de incubação ruminal, desapareceram aproximadamente 55 e $52 \%$ da MS e da PB potencialmente degradáveis, respectivamente. Os desaparecimentos médios da MS e da PB após 48 horas de fermentação ruminal foram bastante próximos de seus respectivos potenciais de degradação, em razão das altas taxas de fermentação.

As características de degradação da PB (Tabela 3) apresentaram a mesma tendência verificada para a MS, o que significa que maior quantidade de proteína escaparia da degradação ruminal no guandu, seguido pela leucena e pelas folhas de mandioca e, em menor extensão, pelo rami e pela soja. A degradabilidade potencial da PB foi maior para o rami (quase 100\%), acompanhado pelas folhas de mandioca, pela soja e pela leucena. O menor potencial de degradação da PB foi observado para o guandu. Essas

Tabela 3 - Parâmetros de degradação ruminal da PB de folíolos e folhas das forrageiras estudadas

Table 3 - Kinetics of ruminal CP degradation of leaflets and leaves of the studied forages

\begin{tabular}{lrcrrr}
\hline $\begin{array}{l}\text { Parâmetro } \\
\text { Item }\end{array}$ & $\begin{array}{r}\text { Leucena } \\
\text { Leucaena }\end{array}$ & $\begin{array}{c}\text { Guandu } \\
\text { Pigeon pea }\end{array}$ & $\begin{array}{c}\text { Soja } \\
\text { Soy }\end{array}$ & $\begin{array}{r}\text { Ramie } \\
\text { Glycine }\end{array}$ & $\begin{array}{c}\text { Mandioca } \\
\text { Cassava }\end{array}$ \\
\hline A (\%) & 93,20 & 88,12 & 93,63 & 98,72 & 95,52 \\
B (\%) & 128,24 & 85,34 & 89,86 & 102,40 & 80,02 \\
c (\%/h) & 6,90 & 1,60 & 15,50 & 10,60 & 9,30 \\
TC (h) & 7,22 & 3,34 & 2,22 & 2,85 & 1,71 \\
S (\%) & 15,29 & 7,23 & 29,98 & 23,02 & 27,24 \\
$\mathrm{~B}_{1}(\%)$ & 77,91 & 80,89 & 63,65 & 75,70 & 68,28 \\
DE (\%) k=0,05 & 60,46 & 26,84 & 78,11 & 74,46 & 71,65 \\
$\mathrm{R}^{2}(\%)$ & 91,64 & 80,55 & 97,56 & 94,69 & 96,83
\end{tabular}

$A$ = potencial de degradação, $B$ = fração degradável, obtida pela equação $\mathrm{P}=\mathrm{A}-\mathrm{Be}^{-\mathrm{ct}}, \mathrm{c}=$ taxa de degradação, $\mathrm{TC}=$ tempo de colonização, $\mathrm{S}=$ fração solúvel, que corresponde à porcentagem de desaparecimento no tempo zero, $\mathrm{B}_{1}=$ fração degradável, obtida por $\mathrm{A}-\mathrm{S}, \mathrm{DE}$ = degradabilidade efetiva, $\mathrm{k}=$ taxa de passagem, $\mathrm{R}^{2}=$ coeficiente de determinação.

$A=$ degradation potencial, $B=$ degradable fraction obtained from the equation $P=A-B e^{-c t}$, $c=$ degradation rate, $C T=$ colonization time, $S=$ soluble fraction, which corresponds to zero time disappearance percentage, $B 1=$ degradable fraction obtained from A-S, $E D=$ effective degradability,$k=$ passage rate, $R^{2}=$ coefficient of determination. 
diferenças na degradabilidade e na digestibilidade podem ser atribuídas a diferenças nas características específicas da proteína, à sua acessibilidade às enzimas digestivas, ou à presença de substâncias antinutricionais, especialmente os taninos ou outros polifenóis, que protegem a proteína e a celulose da degradação ruminal (Van Soest, 1994) e estão presentes em quantidades signifiativas nas folhas de leguminosas arbustivas, como no caso da leucena e do guandu.

Além disso, o teor de NIDA foi negativamente correlacionado à DP da fração protéica das forrageiras $(\mathrm{r}=-0,895)$, de modo que o guandu, que possui maior teor de NIDA, apresentou o menor potencial de degradação e o rami, a maior degradabilidade potencial e o menor conteúdo de NIDA. As DE da proteína (DEP) das forrageiras foram, também, negativamente correlacionadas ao conteúdo de $\operatorname{NIDA}(\mathrm{r}=-0,944)$.

O coeficiente $c$ encontrado para a degradabilidade da PB dos folíolos de guandu foi baixo $(1,60 \% / \mathrm{h})$. A taxa de degradação da fração potencialmente degradável da proteína varia de 2 a 7\%/h (Ruminant, 1985), sugerindo a existência de algum fator que estaria impedindo a digestão ruminal mais eficiente dos folíolos de guandu. Segundo Gonçalves et al. (2004), os taninos são compostos fenólicos com alto peso molecular (500 a 3.000), capazes de formar ligações com proteínas e outras macromoléculas, como carboidratos, diminuindo a degradabilidade ruminal. A presença de taninos, os quais protegem a proteína e a celulose da degradação ruminal (Molina et al., 2002b), também pode ter contribuído para este resultado. Além disso, o guandu, por ser uma forrageira mais fibrosa e com menor conteúdo protéico (Tabela 1), apresentou a menor porcentagem de DEP e, conseqüentemente, a menor taxa de degradação ( $c$, Tabela 3$)$, que, associada ao elevado teor de NIDA, resultou em menor potencial de degradação.

Os folíolos de soja perene e as folhas de rami e de mandioca possuem colonização mais rápida de sua fração protéica, além de mais elevados potenciais e taxas de degradação, resultando em maiores DEP (Tabela 3). Além da alta DP da PB, as folhas de rami e de mandioca e os folíolos de soja e de leucena apresentaram rápido desaparecimento da $\mathrm{PB}$ no rúmen, comprovado pelos valores de $c$.

O desaparecimento da MS dos folíolos de leucena no $\mathrm{t}_{0}$ (fração solúvel - $S$ ) foi duas vezes superior ao da $\mathrm{PB}$, sendo constituída, em sua maior parte $(88,45 \%)$, de material não nitrogenado. A $S$ dos folíolos de guandu apresentou pequena quantidade de nitrogênio solúvel (17,30\%), pois, no $\mathrm{t}_{0}$, o desaparecimento médio da $\mathrm{PB}$ foi $1 / 4$ daquele da MS. Pouco mais de $20 \%$ (21,16\%) da $S$ dos folíolos de soja foram constituídos de compostos nitrogenados, de modo que a solubilidade em água da PB desta forrageira foi a mais elevada entre as estudadas. Todavia, $41 \%$ da $S$ das folhas de rami foi constituída por compostos nitrogenados, apresentando, portanto, solubilidade em água intermediária $(23,02 \%)$. Em folhas de mandioca, a $S$ do material é composta exclusivamente de proteína, justificando a porcentagem de desaparecimento no $\mathrm{t}_{0}$.

Exceto para o guandu (80\%), os coeficientes de determinação $\left(\mathrm{R}^{2}\right)$ foram superiores a $91 \%$, observando-se portanto, bom ajuste das equações exponenciais de $\varnothing$ rskov em relação aos pontos de desaparecimento in situ.

Os elevados potenciais de degradabilidade sugerem que estes alimentos oferecem rápida e abundante disponibilidade de nutrientes para o sistema ruminal. Por essas forrageiras constituírem fontes de nitrogênio potencialmente disponível para os microrganismos (DEP), excetuando-se o guandu, o escape de proteína para os intestinos foi relativamente pequeno, como indicam os valores de PNDR, constantes na Tabela 4. Ressalta-se que a leucena possui potencial relativamente maior $(39,54 \%)$ para suprir proteína aos intestinos que os outros três alimentos, se for considerada a mesma taxa de passagem $(k)$. Esta constatação é confirmada pelos valores de $c$ da $\mathrm{PB}$, que foram mais baixos para os folíolos de leucena (Tabela 3). A porcentagem relativa de digestibilidade da PNDR dos folíolos de leucena foi elevada (73\%) (Tabela 4$)$.

Os folíolos de guandu apresentaram baixo teor de proteína digestível no rúmen (Tabela 4) e, conseqüentemente, elevado escape protéico. No entanto, proteína sobrepassante não é garantia de absorção intestinal eficiente, embora a porção PNDRD de maior interesse tenha sido elevada nos intestinos. A porcentagem relativa de proteína digestível na PNDR (58\%) não foi muito alta, provavelmente em razão do teor de NIDA (26,25\% do nitrogênio total), que foi bastante elevado.

Os folíolos de soja perene apresentaram a mais alta porcentagem de DEP e, conseqüentemente, a menor fração de PNDR. A digestibilidade de sua proteína sobrepassante foi de $63 \%$.

As folhas de rami apresentaram a mais alta digestibilidade da proteína sobrepassante $(80 \%)$ e as folhas de mandioca, a mais baixa (59\%).

A maior parte da proteína das forrageiras estudadas estaria disponível para crescimento microbiano, com pequeno escape de PNDR, mas como todas, exceto o guandu, tiveram baixo conteúdo de PNDR, dietas contendo essas forrageiras requerem suplementos protéicos altos em PNDR para sustentar altas produções. Entretanto, o guandu 
Tabela 4 - Degradabilidade efetiva da proteína (DEP), proteína não degradada no rúmen (PNDR), PNDR digestível (PNDRD), digestibilidade da PNDR (DPNDR) e proteína digestível total (PDT) (\% da PB) dos folíolos e das folhas das forrageiras, para a taxa de passagem de $5 \% / \mathrm{h}$

Table 4 - $\quad$ Protein effective degradability (PED), ruminal undegradable protein (RUP), digestible RUP (DRUP), RUP digestibility (RUPD) and total digestible protein (TDP) (\% of CP) of the forages studied, according a passage rate of $5 \% / h$

\begin{tabular}{lccccc}
\hline $\begin{array}{l}\text { Parâmetro } \\
\text { Item }\end{array}$ & $\begin{array}{c}\text { Leucena } \\
\text { Leucaena }\end{array}$ & $\begin{array}{c}\text { Guandu } \\
\text { Pigeon pea }\end{array}$ & $\begin{array}{c}\text { Soja } \\
\text { Soy }\end{array}$ & $\begin{array}{c}\text { Ramie } \\
\text { Glycine }\end{array}$ & $\begin{array}{c}\text { Mandioca } \\
\text { (folhas) } \\
\text { Cassava } \\
\text { (leaves) }\end{array}$ \\
\hline DEP (PED) & 60,46 & 26,84 & 78,11 & 74,46 & 71,65 \\
PNDR (RUP) & 39,54 & 73,16 & 21,89 & 25,54 & 28,35 \\
PNDRD (DRUP) & 28,73 & 42,19 & 13,86 & 20,54 & 16,85 \\
DPNDR (RUPD) & 72,66 & 57,67 & 63,32 & 80,42 & 59,44 \\
PDT (TDP) & 89,19 & 69,03 & 91,97 & 95,00 & 88,50 \\
\hline
\end{tabular}

${ }^{*} \mathrm{PDT}=\mathrm{DEP}+\mathrm{PNDRD}(T D P=P E D+D R U P)$.

apresentou o mais baixo conteúdo de PDT $(69,03 \%)$ e a menor digestibilidade intestinal da proteína sobrepassante (58\%). Portanto, sua proteína é pouco degradada no rúmen (DEP) e apenas $58 \%$ da porção que passa para o intestino é degradada.

\section{Conclusões}

Das forrageiras estudadas como fonte de proteína para ruminantes, o folíolo de guandu é o menos indicado, pois sua eficiência de aproveitamento no rúmen foi inferior às das demais forrageiras.

Com pequenas variações nas características de degradação ruminal, os folíolos de leucena e soja e as folhas de rami e mandioca constituem-se fontes de proteína adequadas à alimentação dos ruminantes.

\section{Literatura Citada}

AGRICULTURAL AND FOOD RESEARCH COUNCIL - AFRC. Energy and protein requirements of ruminants. An advisory manual prepared by the AFRC Technical Committee on responses to nutrients. Wallingford: $\mathrm{CAB}$ International, 1993. $159 \mathrm{p}$.

BARBOSA, G.S.S.C.; SAMPAIO, I.B.M.; GONCALVES, L.C. et al. Fatores que afetam os valores de degradabilidade in situ da matéria seca de forrageiras tropicais: I. dieta basal. Arquivo Brasileiro de Medicina Veterinária e Zootecnia, v.50, n.6, p.731-735, 1998 .

BRODERICK, G.A. Desirable characteristics of forage legumes for improving protein utilization in ruminants. Journal of Animal Science, v.73, p. 2760-2773, 1995.

GONÇALVES, L.C.; PIRES, D.A.A.; CASTRO, G.H.F. Algumas considerações sobre silagens de sorgo. In: SIMPÓSIO MINEIRO DE NUTRIÇÃO DE GADO DE LEITE, 3., 2004, Belo Horizonte. Anais... Belo Horizonte: Universidade Federal de Minas Gerais, 2004. p.5-16.
LADEIRA, M.M.; RODRIGUEZ, N.M.; GONÇALVES, L.C. et al. Cinética ruminal do feno de Stylosanthes guianensis. Arquivo Brasileiro de Medicina Veterinária e Zootecnia, v.53, n.2, p.1-8, 2001.

McDONALD, I. A revised model for the estimation of protein degradability in the rumen. Journal of Agricultural Science, v.96, n.1, p.251-252, 1981.

MOLINA, L.R.; GONÇALVES, L.C.; RODRIGUEZ, N.M. et al. Degradabilidade in situ das frações fibrosas de silagens de seis genótipos de sorgo (Sorghum bicolor L. Moench) em diferentes estádios de maturação. Arquivo Brasileiro de Medicina Veterinária e Zootecnia, v.54, n.2, p.169-179, 2002a.

MOLINA, L.R.; RODRIGUEZ, N.M.; GONÇALVES, L.C. et al. Degradabilidade in situ da matéria seca e da proteína bruta das silagens de seis genótipos de sorgo (Sorghum bicolor L. Moench), com e sem tanino no grão, ensilados no estádio de grão farináceo. Brazilian Journal of Veterinary Research and Animal Science, v.39, n.5, p.233-237, 2002b.

MOREIRA, J.F.C.; RODRIGUEZ, N.M.; FERNANDES, P.C.C. et al. Concentrados protéicos para bovinos. 1. Digestibilidade in situ da matéria seca e da proteína bruta. Arquivo Brasileiro de Medicina Veterinária e Zootecnia, v.55, n.3, p.315323, 2003.

$\varnothing$ RSKOV, E.R.; McDONALD, J. The estimation of protein degradability in the rumen from incubation measurements weighted according to rate of passage. Journal Agricultural Science, v.92, n.2, p.499-503, 1979.

PULIDO, R.; LEAVER, J.D. Degradabilidad ruminal del forrage disponible en la predera y del aparentemente consumido por vacas lecheras. Pesquisa Agropecuária Brasileira, v.35, n.5, p.1003-1009, 2000 .

QUEIROZ, A.C.; BARBOSA, M.A.; RESENDE, F.D. et al. Suplementação da palhada de milho na alimentação de bovinos. 2. Concentração de amônia ruminal e pH ruminal. Revista Brasileira de Zootecnia, v.27, n.2, p.390-396, 1998.

RUGGIERI, A.C.; TONANI, F.L.; ANDRADE, P. et al. Efeito do emurchecimento e da adição de fubá na degradabilidade in situ da silagem de alfafa (Medicago sativa L.). Arquivo Brasileiro de Medicina Veterinária e Zootecnia, v.53, n.1, p.94-99, 2001.

RUMINANT nitrogen usage. Washington: National Academy Press, 1985. $138 \mathrm{p}$.

SAMPAIO, I.B.M. Experimental designs and modeling techniques in the study of roughage degradation in the rumen and growth of ruminants. Reading: University of Reading, 1988. 228p. Thesis (PhD).

SILVA, D.J.; QUEIROZ, A.C. Análise de alimentos: métodos químicos e biológicos. Viçosa, MG: Universidade Federal de Viçosa, 2002. 235p.

TONANI, F.L.; RUGGIERI, A.C.; QUEIROZ, A.C. et al. Degradabilidade ruminal in situ da matéria seca e da fibra em detergente neutro em silagens de híbridos de sorgo colhidos em diferentes épocas. Arquivo Brasileiro de Medicina Veterinária e Zootecnia, v.53, n.1, p.100-104, 2001.

VAN SOEST, P.J. Nutritional ecology of the ruminant. 2.ed. Ithaca: Cornell University Press, 1994. 476p.

VOLDEN, H.; MYDLAND, L.T.; OLAISEN, V. Apparent ruminal degradation and rumen escape of soluble nitrogen fractions in grass and grass silage administered intraruminally to lactating dairy cows. Journal of Animal Science, v.80, p.2704-2716, 2002 . 